\title{
PERCEPÇÃO DO EDUCADOR FÍSICO SOBRE A ESCOLA PÚBLICA
}

Renato Luz Reis

\section{Resumo}

Esta pesquisa procurou compreender o envolvimento que o educador precisa ter com as pessoas que freqüentam as escolas públicas e sua importância na humanização e formação de seus alunos. Participaram desta pesquisa 25 (vinte e cinco) professores de Educação Física de ambos os sexos e que lecionam na rede pública de ensino estadual, foi utilizado um questionário para a coleta dos dados. Foi verificado que na opinião dos professores entrevistados, o espaço físico adequado $26 \%$, condições materiais $24,7 \%$, são necessárias para a melhoria da escola pública. Os obstáculos que eles encontram são: a política educacional $56,4 \%$ e a legislação $25,7 \%$. As mudanças que eles buscariam seria a busca pela interdisciplinaridade $92,6 \%$. Também $23,3 \%$, dos professores dizem que os outros professores, o vêem como aquele que não sabe ler e escrever e $30 \%$, de trabalhador braçal/manual, e outros $30 \%$, não sofre preconceitos. Os professores se vêem como conscientes de seus atos e que a mudança pela melhoria da escola $69,2 \%$, é a sua motivação para continuar a lecionar. Os professores de Educação Física reconhecem sua importância e tem consciência de seu trabalho para a escola pública, e que ela necessita de melhorias que dependem da política educacional e a interdisciplinaridade.

\section{Palavras-Chaves}

Consciência; Mudança social; Interdisciplinaridade.

\section{PERCEPÇÃO DO EDUCADOR FÍSICO SOBRE A ESCOLA PÚBLICA}

Renato Luz Reis

\begin{abstract}
This research has tried to understand the involvement that the professional of physical education needs to have with people that attend the public schools and your importance in humanization and training of your students. We've been this research with 25 (twenty e five) Physicals Education teachers, women and men who teach in public school of state teaching. We've used a questionnaire in order to collect the results. It was checked out in the opinions of the interviewed teachers: Physical Space Proper $-26 \%$, Conditions of the Materials 24,7\% are necessary to public school to become better. The barrier that they've found are: the educational politics $56,4 \%$ and legislation $25,7 \%$. The changing that they should seek is the interdisciplining $92,6 \%$. Besides $23,3 \%$ of the teachers mentioned that others teachers think that they don't know how to write and read and 30\% labors operators and the others $30 \%$ not suffer by the prejudice. The teachers think they are aware about their conducts and that the changing on the improvement of the school $69,2 \%$ is your motivation to go on to teach. The physical Education teachers know your importance and are aware concerning your work for the public school and that the school needs to be improved that depends on the educational politics and of the inter-disciplining.
\end{abstract}

\section{Key-Words}

Awareness; Social change; Inter-disciplining. 


\section{Referencial Teórico}

\section{A Situação do educador na rede pública de ensino.}

Este trabalho pressupõe uma abordagem crítico-emancipatória, também denominada de crítica ou progressista, conforme Darido (2003), que questiona o caráter alienante da Educação Física na escola, propondo um modelo de superação das contradições e injustiças sociais.

Parte-se da observação feita por Silva (1996) de que a cultura dominante apresenta o indivíduo como ser capaz de autonomia estrita, podendo viver sem depender dos demais desde que, para tanto, possua recursos materiais adequados, mas isso é uma ilusão e falseia a realidade existencial da pessoa que para continuar existindo, como tal, necessita do outro.

O homem, porém, não é totalmente determinado; é um ser autônomo; um ser livre; capaz de superar os condicionamentos sociais da realidade em que vive (SAVIANI, 1993, p. 53). A educação, setor fundamental da vida social deve orientar à promoção do homem. E, enquanto processo de desenvolvimento este, efetivamente tem o homem como preocupação central, dependendo de estrutura e vontade política. Por isso é necessário que os professores encontrem condições para realizá-la (SAVIANI, 2000).

Mudar não é simples Wenzel (1994) diz que, a partir do que esta aí determinado é que deve ser construído o novo, mesmo porque não fazemos parte de outra realidade, não estamos fora dela. Sendo assim, o professor deve construir seu pensamento crítico, avaliar a sua práxis, conscientizando-se e avaliando a sua significação individual e coletiva. "Mudanças e transformações não são simples, mas são possíveis ao sujeito que é crítico" (CAMPOS, 2002, p. 87). A realidade do ensino e da aprendizagem tem no professor o elemento central, ele deve olhar as possibilidades e ver de outra forma. Qualquer mudança significativa começa pelo trabalho dele (CAMPOS, 2002).

Propor e exigir mudanças são apenas os primeiros passos para o longo percurso e dos caminhos difíceis para sua efetivação, é enfrentar as reações mais controversas possíveis (SANTIN, 1987). E, só podem ocorrer num processo de "ação-reflexão-ação", o que significa não pelo trabalho de reprodução simples, mas pela reflexão, questionar os movimentos relacionados com cada contexto sócio cultural (KUNZ, 2001). 
Segundo Silva (1996) esse desejo profundo de mudança para melhor pode deparar com duas possibilidades: ou encontra sua realização mediante ao trabalho ou encontra sua mortificação mediante a lei. Porém, é necessário que o professor mude, sendo criativo e curioso, buscando sempre o melhor para seu educando. Sem curiosidade não há criatividade. A curiosidade nos move e nos põe pacientemente impacientes diante do mundo que não fizemos, acrescentando a ele algo que fazemos (FREIRE, 1996).

Se o professor diante dos problemas insiste e acredita na possibilidade, ele se converte num cidadão otimista, apesar das dificuldades. Porém, ainda assim, encontrará aqueles que não correspondem a suas expectativas e passam a ver os fatos como não possíveis de mudanças (CAMPOS, 2002).

Todo professor deve ter em sua atuação a dimensão investigativa, tornando os elementos de sua prática objeto de análise e reflexão. E esses objetivos têm de ir de encontro com as necessidades de seu educando (VAZ, 2002). A educação é uma prática de libertação, uma troca, educador - educando, pensando, dialogando, optando, participando e transformando. O pensamento crítico deve ser entendido e estendido aos alunos, para que possam ter consciência política e critica e que façam valer seus direitos por uma educação de qualidade (FERREIRA NETO, 1994). Sem crítica o novo não acontece, o desejado discurso do diverso não se enuncia à coesão consciente não supera a homogeneização coletivista, a própria proposição científica morre (CUNHA, 1991).

Barbosa (1997) se pergunta, como poderá o professor querer mudar uma situação dada a ele, se na verdade, ele continuar pensando de uma maneira tradicional e conservadora? A leitura e a reflexão, segundo ele, farão com que o professor seja agente de dois processos de transformação: primeiramente uma transformação interna no seu modo de entender as relações sociais, depois, uma transformação externa colaborando com a transformação social, ajudando outras pessoas a entenderem o que ele conseguiu entender.

\section{O Que é a Escola Pública}

A escola deve atuar na preparação intelectual e moral dos alunos para assumir sua posição na sociedade. Assim é necessária a presença de um professor que intervenha para ajudar o aluno a suprir suas demandas e criar outras, para ganhar autonomia, para ajudá-lo no seu esforço de distinguir a verdade do erro e as realidades sociais. É nela que ele irá aprender o valor da vida (LIBÂNEO, 1995). A escola é o laboratório onde o educando será transformado em cidadão, na medida em que ele assume determinados 
comportamentos importantes à vida adulta (SANTOS, 2001). "É o lugar onde se materializa o objetivo máximo do sistema escolar, ou seja, o entendimento direto de seus usuários nas relações de ensinoaprendizagem" (SILVA, 1996, p. 42).

Desse modo, deveria trabalhar não na transmissão pura e simples de informação, mas ser um espaço de cultura onde se realiza uma meditação reflexiva sobre as transformações sociais; um espaço para questionar criticamente, pensar, sentir e atuar. (PIMENTA, 2002).

Os professores da rede pública de educação em geral, entretanto, sentem dificuldades em desenvolver seu trabalho por diferentes restrições oriundas da qualidade do espaço físico, dos materiais adequados à prática educacional deles, do apoio que lhes facilite o trabalho, da atualização necessária e dos baixos salários (BATISTA, 2003). Já os professores de Educação Física, por necessitarem de espaço físico adequado às suas aulas, bolas, redes e demais materiais não conseguem contribuir de forma positiva para realizarem-se como professor.

A localização é um outro aspecto que dificulta o trabalho desses professores. Quanto mais distantes do centro estas escolas estão, menor atenção das autoridades recebe. O professor de Educação Física Escolar também se desmotiva devido aos baixos salários e a desvalorização da profissão (FERREIRA, 1994). Além disso, outro aspecto desmotivador é a redução do professor a mero repassador de informação, sendo substituído por projetores e vídeos, que não são discutidos. Assim não conseguem ser transformadores da escola nem dos alunos (WENZEL, 1994). Um último fator é que por falta de uma maior conscientização dos alunos, eles não buscam na escola uma forma de melhorar suas vidas, não sentem prazer em estudar.

A escola com objetivos necessita de um plano, um projeto. Sendo "a construção do projeto pedagógico na escola um trabalho coletivo de professores e pedagogos empenhados em colocar sua profissão a serviço da democratização da educação em nosso país" (PIMENTA, 2002).

O professor deve sempre repensar sua prática, refletir sobre suas ações e entender que o aluno é o centro do processo de ensino aprendizagem (MOREIRA, 2004). "Superar a educação deformada pelo travamento da sua dimensão crítica, reflexiva e dialógica é a única razão pelo qual ainda se pode falar eticamente em projetos pedagógicos" (BETTI, 2003, p. 41). Tem que ter em mente que ele é um agente 
do processo de desenvolvimento físico e mental de seu aluno, o produto final da sua ação docente tem que interessar a alguém, o educador tem de ter compromisso com a transformação da realidade da sociedade (PEREIRA, 1988).

A prática educativa, os objetivos, os sonhos que se perseguem nessa prática não permitem que a escola seja neutra, mas política sempre (FREIRE, 1995), a maior contribuição dela seria elevar o nível de conhecimento da classe trabalhadora, de prover-lhe de conhecimento que atenda aos seus interesses (WENZEL, 1994).

O homem enquanto unidade corpo e espírito possue o poder transcendental da reflexão. E, a Educação Física é a disciplina que o envolve como conjunto em sua relação com a realidade social. Os valores da educação em geral e seus respectivos objetivos estendem-se em sua totalidade a formação do homem, tanto pessoal como social. Sendo assim, o educador físico não deve se formar como amestrador de alunos, mas sim ser formado para ensiná-los a pensar, a sentir o porquê de cada movimento que lhes é passado. Mostrar os benefícios de cada movimento para o seu corpo e mente (GONÇALVES, 1997).

A principal atitude do professor para com a criança é a de ensiná-la a vivenciar os valores humanos, a cooperação, a responsabilidade, a amizade. Ele pode utilizar jogos com regras criadas pelos próprios alunos e com o professor, podendo modificá-las depois. Isto faria com que a criança participasse e percebesse sua importância. A formação humana tem de ter relação com o desenvolvimento da criança como pessoa, e ser capaz de ser propiciadora, junto com outras, de um espaço humano de convivência social desejável (PEREZ GALLARDO, 2004).

“O acento principal está no termo 'humano', é o homem como um todo que se movimenta, o homem como um ser que pensa, sente e age, existindo em um mundo com o qual interage dialeticamente" (GONÇALVES, 1997, p. 141).

A responsabilidade de definir e contextualizar o papel da Educação Física diante do projeto pedagógico da escola, mais do que nunca está se difundindo em cada unidade educativa. O professor agora deve dialogar executar e redimensionar os propósitos que norteiam suas ações pedagógicas na área da Educação Física (SANTOS, 2001). Ela tem grande influência na escola, pois colabora para que os conteúdos de outras disciplinas sejam reforçados durante as aulas curriculares (PEREIRA, 1988). E, deve ser vista como inserta numa práxis social com estreitas relações no plano sócio - político - cultural, deve 
ampliar o mundo do movimento das crianças, respeitando-se o contexto de mundo vivido das mesmas (KUNZ, 2001). Segundo Zabala (1998) é necessário que o professor pergunte-se, o que ensinar? Devendo acrescentar a resposta por que ensinar? E como ensinar?

Os teóricos visualizam a Educação Física como instrumento de veiculação da ideologia dominante, alienada e alienante (CASTELLANI, 2000). Porém, Barbosa (1997) propõe que o papel da Educação Física Escolar seja o de formar cidadãos críticos, autônomos e conscientes de seus atos, visando uma transformação social.

"Não existe programa único a ser cumprido. Geralmente... em escolas públicas, o professor elabora seu programa de acordo com suas expectativas. Esta possibilidade nos abre espaço para elaborarmos um currículo que realmente vise uma transformação social (BARBOSA, 1997, p. 24).”

A Educação Física tem uma grande influência para a melhoria do homem. Os professores de Educação Física reconhecem que todas as disciplinas escolares procuram preparar o aluno para a vida em sociedade, mas, são eles que se vêem com mais condições para esta tarefa, justamente pelo trabalho sobre e por meio do corpo que permite uma atuação global nos educando. É com base nessa idéia que devemos auxiliar os nossos alunos transformá-los em seres pensantes e críticos sobre todas as informações que lhes chegam, devemos mostrar-lhes a sua capacidade enquanto "ser" (DAOLIO, 1995).

O que será que acontece para não fazermos esta mudança? Talvez não seja interessante para a classe dominante que os professores formem pessoas com essas características? As aulas de Educação Física devem deixar espaço para os aspectos cognitivos e para os debates, para a problematização tanto nos aspectos políticos, sociais e culturais que envolvem o ambiente educativo (PEREIRA, 1988). As tarefas devem trazer aprendizagens significativas para o aluno, levando-o a uma atitude consciente de seus atos no seu mundo (OLIVEIRA, 1985).

Para Betti (1991) o modelo sociológico indica um direcionamento no processo de socialização e formação da personalidade propiciada pela atividade física na escola, se concebe o educador como agente consciente dos processos e das determinações de seu trabalho.

(Nós Educadores Físicos) lutamos diariamente contra os preconceitos a que nossa profissão e os profissionais são submetidos. Parte desta culpa é nossa. Pelas características de nossa atividade, 
pela nossa postura, pelos profissionais que somos e pelo imobilismo que tivemos por muitos anos. Cabe a nós, profissional da área, vencer esta batalha pela melhoria de nossa profissão, pelo reconhecimento de nossa importância, pela conquista de nosso espaço, pela descoberta de nossa função" (PAIÂNO, 2006, p. 56).

Objetivo Geral: verificar o contexto do professor de Educação Física quanto ao seu trabalho e real papel na rede pública de Ensino.

\section{Objetivos Específicos:}

- Identificar com o professor de Educação Física o que ele sabe sobre a escola pública;

- Verificar quais obstáculos / resistências às mudanças o educador físico encontra na escola pública;

- Identificar o papel desse profissional na escola pública.

\section{Método}

Participantes - Participaram desta pesquisa 25 (vinte e cinco) professores de Educação Física de ambos os sexos, com idade entre 25 e 45 anos, que lecionam na rede pública de ensino estadual, da Zona Leste da cidade de São Paulo.

Material - Para cumprir os objetivos propostos nesta pesquisa de campo, foi utilizado para a coleta de dados, um questionário

(Anexo A) com 12 perguntas fechadas, elaboradas pelo pesquisador e orientador, que os professores responderam voluntariamente; uma carta para autorização da pesquisa a direção das escolas.

(Anexo B); uma carta de Termo de Consentimento Livre e Esclarecido para cada um dos professores (Anexo C). A pesquisa tem como número de processo CEP: 0662006 e o CAAE: 0066.0.237.000-06.

Procedimentos - Foi solicitada a direção das escolas participantes a autorização (Anexo B) para a aplicação da pesquisa em cada uma das escolas. Após a autorização o Autor contatou os professores, e explicou o objetivo da pesquisa e solicitou as respectivas participações como voluntários, a aplicação do instrumento foi de forma individual na própria instituição, foi solicitada a assinatura do Termo de 
Consentimento Livre e Esclarecido (Anexo C) para que os mesmos pudessem participar da pesquisa de forma voluntária. Sendo que nessa ocasião foi garantido aos participantes o sigilo absoluto de sua identidade pessoal e institucional, considerando que os dados da coleta seriam utilizados unicamente para fins da pesquisa.

\section{Resultados e Discussão}

Os resultados da pesquisa são oriundos da análise quantitativa e qualitativa, feita por meio de questionário aplicado, conforme (Anexo A).

\section{Tabela 1 - Necessidades de melhoria da escola}

\begin{tabular}{ccc}
\hline Alternativas & F & $\%$ \\
\hline Condições materiais & 17 & 24,7 \\
Direção escolar & 3 & 4,3 \\
Participação de alunos & 8 & 11,6 \\
Espaço físico & 18 & 26,0 \\
Projeto pedagógico & 6 & 8,7 \\
A participação da comunidade & 6 & 8,7 \\
A participação dos professores & 11 & 16,0 \\
\hline TOTAL & 69 & 100
\end{tabular}

O número de freqüência está acima da quantidade de participantes por que os entrevistados assinalaram mais de uma alternativa.

A Tabela 1 mostra que para os professores de Educação Física entrevistados, o espaço físico (26\%) é uma das principais necessidades de melhoria da escola pública; as condições materiais $(24,7 \%)$ também são vistas como fator essencial para a melhoria dessa escola. Segue-se a esses fatores à participação de professores (16\%) e participação de alunos (11,6\%). Indo de encontro com Batista (2003) os professores da rede pública de educação sentem dificuldades em desenvolver seu trabalho pelas seguintes razões: o espaço físico, materiais adequados. 
O projeto pedagógico e a participação da comunidade com $8,7 \%$ têm certa relevância na opinião dos entrevistados. Ele deve fazer parte da política educacional sem a participação desses dois s escola não consegue seguir um método de trabalho.

Esses resultados mostram a escala de obstáculos que o entrevistado percebe em sua prática. Disso inferese que a superação de um leva ao outro: espaço físico adequado e condições materiais; o projeto pedagógico levado a sério e participação de alunos e professores de forma responsável e comunidade em prol da escola, podem resultar numa escola pública melhor. Em principio, parece-nos que a linha de menor resistência é a direção da escola, com 4,3\%, aparece em último lugar, na opinião do professor, como obstáculo à melhoria da escola.

É importante salientar que não devemos ficar estáticos. Precisamos tomar decisões e começarmos a mudar essa situação para melhor. Campos (2002) diz que se o professor diante dos problemas insiste e acredita na possibilidade de superar os obstáculos, ele é um cidadão otimista. Somando-se as dificuldades materiais, ele ainda encontrará colegas acomodados, que não correspondem a suas expectativas e vêem os fatos como não possíveis de mudanças.

Ficam aqui algumas perguntas para a reflexão dos professores: Como fazer essa mudança pela Educação Física? Deixando de ser alienado? Que mudança o professor deve fazer em sua prática?

Tabela 2 - Obstáculos para melhoria da escola

\begin{tabular}{ccc}
\hline Alternativas & F & $\%$ \\
\hline Legislação & 10 & 25,7 \\
Professores & 2 & 5,1 \\
Falta de Materiais & 5 & 12,8 \\
Política Educacional & 22 & 56,4 \\
\hline TOTAL & 39 & 100,0
\end{tabular}

O número de freqüência está acima da quantidade de participantes por que os entrevistados assinalaram mais de uma alternativa. 
Na Tabela 2 verifica-se que a política educacional 56,4\% é o principal obstáculo para a melhoria da escola pública, seguido da legislação 25,7\%. Sendo esses os obstáculos para a melhoria da escola, como coloca Silva (1996) o desejo profundo de mudança para melhor pode deparar com duas possibilidades: ou encontra sua realização mediante o trabalho ou encontra sua mortificação mediante a lei.

O homem, porém, não é totalmente determinado; é um ser autônomo; um ser livre; capaz de superar os condicionamentos sociais da realidade em que vive (SAVIANI, 1993, p. 53). No entender do Autor o trabalho está relacionado aos limites impostos pela política educacional, o que está sendo feito para a escolha da melhor maneira para se educar os alunos das escolas públicas.

Para o Autor os professores 5,1\% não se vêem como obstáculo a essa melhoria, mas como solução. Na opinião deles, a falta de materiais 12,8\% também não se configuram como obstáculo.

Tabela 3 - O que você mudaria para a melhoria da escola

\begin{tabular}{lcc}
\hline Alternativas & F & $\%$ \\
\hline Busca da Interdisciplinaridade & 25 & 92,6 \\
Forma de trabalhar & 2 & 7,4 \\
\hline TOTAL & 27 & 100 \\
\hline
\end{tabular}

O número de freqüência está acima da quantidade de participantes por que os entrevistados assinalaram mais de uma alternativa.

Na Tabela 3 em relação à mudança que o professor faria na escola pública seria a busca pela interdisciplinaridade com 92,6\% que vai de encontro com Pimenta (2002) o projeto pedagógico na escola é um trabalho coletivo de professores empenhados em colocar sua profissão a serviço da democratização do ensino, Silva (1996) diz que a cultura dominante apresenta o indivíduo como ser capaz de autonomia estrita, podendo viver sem depender dos demais desde que, para tanto, possua recursos materiais adequados, mas isso é uma ilusão e falseia a realidade existencial da pessoa que para continuar existindo, como tal, necessita do outro.

O Autor entende que esse resultado demonstra que a interdisciplinaridade não está ocorrendo, os professores estão encontrando dificuldades para trabalharem com ela. A interdisciplinaridade pode 
ocorrer por meio da Educação Física, pois para Pereira (1988) elas têm grande influência na escola, pois colabora para que os conteúdos de outras disciplinas sejam reforçados durante as aulas curriculares

Com 7,4\% a forma de trabalho é um fator de pouca influência na tabela, mas que mostra que alguns professores estão descontentes com sua própria prática. Como coloca Campos (2002) o professor deve construir o pensamento critico e avaliar a sua prática, articulando com outras disciplinas e ciências.

É importante salientar que um dos entrevistados gostaria na escola um maior: "Investimento do Estado na melhoria (reforma) da escola". Mostrando a insatisfação da atuação dos governantes em relação à Educação.

Tabela 4 - Quais preconceitos que os professores sofrem

\begin{tabular}{llc}
\hline Alternativas & F & $\%$ \\
\hline Não saber escrever, nem se expressar & 7 & 23,3 \\
De trabalhador manual & 9 & 30,0 \\
Todos citados acima & 3 & 10,0 \\
Outros tipos de preconceito & 2 & 6,7 \\
Não sofre preconceito & 9 & 30,0 \\
\hline & & \\
TOTAL & $\mathbf{3 0}$ & $\mathbf{1 0 0}$ \\
\hline
\end{tabular}

O número de freqüência está acima da quantidade de participantes por que os entrevistados assinalaram mais de uma alternativa.

Na Tabela 4 observa-se que o professor de Educação Física sofre preconceitos, o que não é bom para esses profissionais. Os resultados mostram que de 23,3\% dos professores entrevistados reconhecem que os outros professores de outras disciplinas o vêem como aqueles que não sabem ler e escrever, nem expressar suas idéias. Outros 30\% dizem ser este o trabalhador manual da Escola Pública, o profissional que quando é necessário “carregar piano" ele está lá. Uma parte dos entrevistados 30\%, diz que o professor de Educação Física não sofre preconceito pelos outros professores.

É importante frisar que, alguns dos entrevistados dizem que um outro tipo de preconceito que sofrem é o de: "não é valorizado como profissional” e que a "Educação Física serve para castigar os alunos, se 
eles não se comportam (lição) não fazem aula, Educação Física só serve para isso" o que representa $6,7 \%$. Pâiano (2006) alerta para a necessidade de se lutar diariamente contra os preconceitos envolvendo esses profissionais. E isso mostra que essa luta não pode se arrefecer precisa ganhar corpo e tem de ser a mais rápida possível, pois é obrigação dessa categoria mostrar seu valor e o valor de sua profissão.

\section{Tabela 5 - Qual motivação o educador físico tem para lecionar na escola pública}

\begin{tabular}{lcc}
\hline Alternativas & F & $\%$ \\
\hline Mudança na escola e sociedade & 18 & 69,2 \\
Por ser fácil para trabalhar & 6 & 23,0 \\
Por marketing de ser professor & 1 & 3,9 \\
Outros & 1 & 3,9 \\
\hline TOTAL & $\mathbf{2 6}$ & $\mathbf{1 0 0}$ \\
\hline
\end{tabular}

O número de freqüência está acima da quantidade de participantes por que os entrevistados assinalaram mais de uma alternativa.

Na Tabela 5 destacamos que com $69,2 \%$ a motivação do professor de continuar na escola pública está ligada à mudança na escola e na sociedade, o que é um ótimo sinal, pois, ainda temos a esperança de que os profissionais da escola pública estejam preocupados em mudar a sociedade desigual onde ele está, e fazer a diferença é um dever do professor de Educação Física. Como coloca Pereira (1988) que o educador tem que ter em mente que ele é um agente do processo de desenvolvimento físico e mental de seu aluno, o produto final da sua ação docente tem que interessar a alguém, o educador tem de ter compromisso com a transformação da realidade da sociedade.

Uma parte coloca que a estabilidade empregatícia e a facilidade de trabalhar com $23 \%$, mostrando que isso também é um fator que o motiva à continuar a lecionar na escola. É triste saber que alguns professores trabalham na escola pública para fazerem marketing pessoal 3,9\%, o que é um sinal de que alguns atrapalham o trabalho de profissionais de sua área, os que querem mudar algo na sociedade. Para Pimenta (2002) a escola deveria trabalhar não na transmissão de informação, mas deveria ser um espaço de cultura onde se realiza uma meditação reflexiva entre as transformações sociais; um espaço para questionar criticamente, pensar, sentir e atuar. 


\section{Conclusão}

A partir dos resultados apresentados podemos salientar que o professor de Educação Física reconhece sua importância na atividade escolar e de sua importância numa criação de uma sociedade melhor e de pessoas melhores, ele reconhece ainda que necessite melhorar sua atuação na escola, e busca por ajuda de todos que fazem parte da escola pública, porém encontra dificuldades, vendo na interdisciplinaridade uma alternativa, uma possível solução para a melhoria da escola.

É extremamente desagradável saber que um profissional de tanta responsabilidade, como é o professor de Educação Física na escola e na sociedade, sofra algum tipo de preconceito ou discriminação. Infelizmente é culpa do professor, dos profissionais, que não se dão o devido valor, somos parte da educação de nosso país temos que mudar e refletir sempre, sobre que profissionais nós somos, e o que estamos fazendo na escola. Felizmente depende de nós mudarmos essa característica que nos foi dada de profissional que não pensa, não sabe escrever, não sabe se expressar depende somente da postura do professor basta ele aceitar a crítica e mudar sua postura.

O professor está à procura de ajuda, ele sabe da importância de se unir, de formar uma aliança com todos que fazem parte da escola, professores, alunos, diretores e pais, comunidade para a melhoria da escola e de sua prática. O professor de Educação Física percebe seu papel e os problemas que a escola pública onde ele está tem problemas. É importante saber que o que motiva o professor a lecionar na escola pública é a esperança de querer mudar, ajudando na formação do aluno, o futuro cidadão que vive em uma sociedade em que: quem tem vive e quem não tem sobrevive, o professor deve fazer sua parte para a melhoria da sociedade e da educação no Brasil.

O professor não deve esperar, e sim fazer sua parte, lembrar que não está sozinho na escola, precisa de todos, diretores, professores, funcionários da escola, pais, alunos e comunidade para buscar continua transformação da nossa sociedade, que o professor se atualize e saiba perguntar: será que está ótimo? Eu preciso melhorar! Que ele não caia no comodismo! Que ele mude sempre para melhor, é o que esperamos.

No curso da pesquisa o Autor percebeu que é importante relembrar o professor que ele também necessita da ajuda das outras disciplinas, pois não adianta querer mudar somente a Educação Física, pois a interdisciplinaridade envolve todos que fazem parte da rede pública de ensino. Não podemos ser 
melhores sozinhos, dependemos dos que fazem parte da sociedade, os cursos preparam pessoas para atuarem nas escolas, necessitamos da ajuda de mais profissionais, que buscam ser sérios e responsáveis em sua prática. Se o homem em geral precisa ser transformado, precisa estar aberto à mudança sempre. Para tanto devemos buscá-la para melhorar o nosso convívio com outras pessoas.

O Autor compreende que o papel do professor na unidade pública de ensino é muito importante na formação do aluno, será que o professor pensa em mudar ou quer mudar esse conceito? Percebe que mudança não é tão simples, mudar algo que já está posto em nossa frente e em nossa cabeça há muito tempo, mas, nós, professores de Educação Física, temos que ter consciência do nosso papel e não sermos apenas meros repassadores de informação pronta, "adestradores", "rola-bola", sem ao menos, mostrar aos nossos alunos o porquê do conteúdo que está sendo passado e onde eles irão utilizar esse novo conhecimento que está chegando a suas vidas.

Será que queremos ser vistos como aquele que fala errado? Que não participa ativamente das reuniões? Entre outras coisas que são ditas pelo senso comum? Percebe que é importante lembrar que o professor também precisa mudar sua postura, para transformar esses alunos e essa escola, os educadores não podem ter medo de mudar e nem de receberem críticas sobre o seu trabalho. Podem muito bem transformar-se em melhores profissionais, mas depende de todos que fazem parte da escola. Porém, não devemos desistir de tentar, mesmo que essa transformação seja pouca, mas, um dia, transforma-se em muito, temos que acreditar no professor e na sua capacidade.

\section{Referências}

BATISTA, L. C. C. Educação Física no ensino fundamental. 2. ed. Rio de Janeiro: 2003.

BARBOSA, C. L. A. Educação Física Escolar. 3. ed. Rio de Janeiro: Vozes, 1997.

BETTI, M. Educação Física e mídia: novos olhares, outras práticas. São Paulo: Hucitec, 2003.

BETTI, M. Educação Física e sociedade. São Paulo: Movimento, 1991.

CAMPOS, N. P. A construção do olhar estético-crítico do educador. Florianópolis: Ed. da USF, 2002.

CASTELlANI FILHO, L. Educação Física no Brasil: a história que não se conta. 5. ed. Campinas: Papirus, 2000.

CUNHA, M. S. V. Educação Física ou ciência da motricidade humana. Campinas: Papirus, 1991. 
DARIDO, S. C. Educação Física na escola: questões e reflexões. Rio de Janeiro: Guanabara Koogan, 2003.

DAOLIO, J. Da cultura do Corpo. 10. ed. Campinas: Papirus, 2005.

FERREIRA NETO, A. F. Educação Física: ensino e realidade. Ed. da UFES, 1994.

FREIRE, P. A Educação na cidade. 2. ed. São Paulo: Cortez, 1995.

. Pedagogia da autonomia: saberes necessários à prática educativa. São Paulo: Paz e Terra, 1996.

PEREZ GALLARDO, J. S. Educação Física: contribuições à formação profissional. 4. ed. Íjui: Ed. da Unijuí, 2004.

GONÇALVES, M. A. S. Sentir, pensar, agir: corporeidade e educação. 2. ed. Campinas: Papirus, 1997.

KUNZ, E. Educação Física: ensino e mudanças. 2. ed. Ijuí: Ed. da Unijuí, 2001.

LIBÂNEO, J. C. Democratização da escola pública. 13. ed. São Paulo: Loyola, 1995.

MOREIRA, C. E. Educação Física escolar: desafios e propostas. Jundiaí: Fontoura, 2004.

OLIVEIRA, V. M. Educação Física humanista. Rio de Janeiro: Ao Livro Técnico, 1985.

PAIÂNO, R. Possibilidades de orientação da prática pedagógica do professor de educação física: situações de desprazer na opinião dos alunos. Revista Mackenzie de Educação Física e Esportes, v. 5, 2006. Disponível em: http//: www.mackenzie.com.br/editoramackenzie/revistas/edfisica5n1/art4/edfis/. Acesso em: 17 nov. 2006.

PEREIRA, F. M. Dialética da cultura física. São Paulo: Ícone, 1988.

PIMENTA, S. G. De professores, pesquisa e didática. Campinas: Papirus, 2002.

SANTIN, S. Educação Física: uma abordagem filosófica da corporeidade. Ijuí: UNIJUI, 1987.

SANTOS, E. S. Olho mágico: cotidiano, o debate e a crítica em educação física. Canoas: ULBRA, 2001.

SAVIANI, D. Educação brasileira: estrutura e sistema. 8. ed. Campinas: Autores Associados, 2000.

SAVIANI, D. Educação: do senso comum à consciência filosófica. 11. ed. Campinas: Autores Associados, 1993.

SILVA, J. M. da. A autonomia na escola pública. Campinas: Papirus, 1996.

VAZ, A. F.; SAYÃO, D. T.; PINTO, F. M. Educação do corpo e formação de professores: reflexões sobre a pratica de ensino de educação física. Florianópolis: Ed da UFSC, 2002.

WENZEL, R. L. Professor: agente da educação? Campinas: Papirus, 1994.

ZABALA, A. A prática educativa: como ensinar. Porto Alegre: Artmed, 1998. 


\section{Anexo A}

\section{Questionário}

Agradecemos sua participação nesta pesquisa. Nosso objetivo é verificar o contexto do professor de Educação Física quanto ao seu trabalho e real papel na rede pública de Ensino. Essas informações são muito importantes para coleta de dados e a realização do PVIC. Não existem questões certas ou erradas. Você não deve se identificar. Nós garantimos absoluto anonimato e sigilo de suas respostas, as quais serão usadas somente com finalidades científicas. Suas respostas são muito importantes. Por favor, responda todas as questões de maneira completa. Se você tiver alguma dúvida pergunte ao pesquisador.

\section{O que é preciso melhorar na escola pública?}

( ) Condições materiais

( ) A direção da escola

( ) A participação dos alunos

( ) Espaço físico
( ) O projeto pedagógico

( ) A participação da comunidade

( ) A participação dos professores

\section{Em sua opinião qual o maior obstáculo para a melhoria da escola pública?}

( ) A legislação.

( ) A direção da Escola.

( ) Os professores.

( ) A falta de materiais.

( ) A política educacional

\section{O que você mudaria para melhorar a escola pública?}
A. ( ) Buscaria Interdisciplinaridade.
C. ( ) Mudaria minha forma de trabalhar.
B. ( ) Não é possível mudar..
D. ( ) Ela está boa.

\section{O professor de Educação Física contribui para mudança na escola?}

( ) Sim ( ) Não ( ) Sim, somente em sua área.

5. Em sua opinião a Educação/Educação Física contribui para a melhoria das condições sociais dos alunos?

( ) Sim ( ) Não 
6. Em sua opinião, como o professor de Educação Física é visto pelos outros educadores?

( ) Alienado / passivo, sem participação e sem perspectiva de mudança.

( ) Interessado sobre os assuntos gerais de escola.

( ) Profissional reflexivo.

( ) Como profissão ativo em sua função.

7. Quais os preconceitos sofridos pelo professor de Educação Física?

( ) Não sabe escrever, nem expressar suas idéias

( ) Só faz trabalhos manuais / braçal, em épocas de eventos festivos.

( ) Todas citadas acima

( ) Sofre outro tipo de preconceito Qual?

( ) Não sofre preconceito

8. Como se caracteriza a atitude do professor de Educação Física na Escola Pública?

( ) Não busca mudança para melhor ( ) Não reflete sobre seus atos

( ) Ele tem consciência do trabalho como educador

( ) Está focado apenas em sua prática pedagógica

9. Em sua opinião como está a Educação Física na Escola?

( ) Ótima ( ) Ruim

( ) Sofrível ( ) Boa

10. Qual o espaço por excelência do professor de Educação Física na Escola Pública?

( ) Sala de Aula

( ) Quadra

( ) Todos os espaços da Escola

( ) Outro. Qual?

11. De que maneira sua disciplina poderá contribuir para a formação do aluno?

( ) Social.

( ) Somente Corporal.

( ) Corporal e Social. ( ) Pouca contribuição. 


\section{O que motiva o educador físico a lecionar na escola pública?}

( ) Mudança na escola e na sociedade.

( ) Por ser fácil para trabalhar, e segura em relação a estabilidade no emprego.

( ) Por marketing de ser professor.

( ) Outros 
Anexo B

Autorização

Mogi das Cruzes, 00 de Fevereiro de 2007.

\section{Prezado Diretor (a):}

Vimos por meio deste, solicitar autorização para que possamos realizar uma pesquisa com objetivo de verificar o contexto do professor de Educação Física quanto ao seu trabalho e real papel na rede pública de Ensino.

Todo esse trabalho será desenvolvido seguindo rigorosamente as normas éticas do Conselho Federal de Educação Física e dos órgãos oficiais que regulamentam a pesquisa científica, portaria CNS 196-96, resolução do Ministério da Saúde em pesquisa com seres humanos. Garantindo total sigilo quanto à identificação dos voluntários, sendo os dados utilizados somente para fins científicos.

A participação da Instituição é de fundamental importância, contudo, ela é absolutamente voluntária, podendo o interessado desistir a qualquer momento. Sendo assim, caso autorize a realização desta pesquisa na mesma, expresse sua autorização assinando o termo de consentimento abaixo.

Vale salientar que os resultados serão divulgados para a Universidade de forma que não identifique os voluntários da pesquisa.

\section{Termo de Autorização}

Declaro ter sido devidamente informado sobre os objetivos da presente pesquisa e autorizo a realização da mesma na Instituição de Ensino.

Assinatura:

Cargo:

Escola: 
Anexo C

\section{Termo de Consentimento Livre e Esclarecido}

$\mathrm{Eu}$, , de livre e espontânea vontade, sem esforço ou coagido, aceito participar da pesquisa "Percepção do educador físico sobre a escola pública".

O trabalho será executado pelo aluno Renato Luz Reis principal investigador, e será apresentada a Universidade de Mogi das Cruzes (UMC) tendo como objetivo verificar o contexto do professor de Educação Física quanto ao seu trabalho e real papel na rede pública de Ensino.

Para a realização da pesquisa estou ciente de que será aplicado um questionário para a coleta de dados. Estou ciente que todas as informações obtidas durante o curso do estudo permanecerão confidenciais, de forma que só os investigadores principais saberão a minha identidade e serão as únicas pessoas que manterão informações sobre o assunto.

Estou ciente que nenhum benefício especial, compensação ou remuneração será concedido só por causa da minha participação nessa pesquisa, sendo minha participação absolutamente voluntária, podendo este consentimento, ser retirado a qualquer hora e a qualquer momento, e poderei desistir de fazer parte da pesquisa.

Terei o direito de qualquer investigação relativa à pesquisa e entendo que posso contatar Renato Luz Reis para maiores esclarecimentos sobre esta pesquisa ou sobre minha participação.

Eu li e entendi todas as informações contidas nesse termo de consentimento.

Assinatura do voluntário:

RG:

Data: 12007.

Renato Luz Reis

(pesquisador) 


\section{Renato Luz Reis}

Universidade de Mogi das Cruzes 2007

Rua: Morro dos Olhos d água, 393 - Itaquera - S P

rena-Ir@ig.com.br - (11) 2524-6003 / 8192-4944

Orientador:

Professor Ms. Airton Andrade Leite

Pesquisa elaborada para o Programa Institucional Voluntário de Iniciação Cientifica PVIC da Universidade de Mogi das Cruzes (UMC). 